\title{
Idade à Desmama e Manejo Alimentar na Produção de Cordeiros Superprecoces ${ }^{1}$
Antonio Sérgio Villas Bôas ${ }^{2}$, Mario De Beni Arrigoni ${ }^{3}$, Antonio Carlos Silveira ${ }^{4}$, Ciniro Costa ${ }^{3}$, Luiz Artur Loyola Chardulo4, 5

\begin{abstract}
RESUMO - O objetivo do presente trabalho foi verificar o efeito da suplementação das ovelhas sobre a época da desmama, na produção de cordeiros superprecoces e no ciclo reprodutivo da mãe. Foram utilizadas 66 fêmeas da raça Hampshire Down, com idade entre 3 e 4 anos, e seus respectivos produtos, mantidos em pastagem de gramínea e alimentados em creep-feeding com ração concentrada. As ovelhas foram distribuídas em suplementadas $(n=34)$ e não suplementadas $(n=32)$ durante a lactação. Os cordeiros foram distribuídos ao acaso em quatro tratamentos: T1 - cordeiros desmamados aos 34 dias $(n=16)$ com ovelhas suplementadas; T2 - cordeiros desmamados aos 62 dias ( $n=18)$ com ovelhas suplementadas; T3 - cordeiros desmamados aos 34 dias de idade ( $n=16)$, com ovelhas não suplementadas e; T4 cordeiros desmamados aos 62 dias $(n=16)$ com ovelhas não suplementadas. O delineamento experimental foi o de blocos ao acaso, com arranjo fatorial $2 \times 2$. Os cordeiros dos tratamentos $\mathrm{T} 2 \mathrm{e} \mathrm{T} 4$ tiveram ganhos de peso significativamente maiores que os desmamados aos 34 dias (T1 e T3). O peso à desmama aos 62 dias foi significativamente maior nos cordeiros de mães não suplementadas e os cordeiros foram abatidos mais cedo que os de ovelhas suplementadas. Os rendimentos de carcaça e o índice de compacidade foram superiores nos cordeiros desmamados aos 62 dias. Não houve diferença significativa na gordura de cobertura. Houve efeito de suplementação das mães na maciez da carne dos cordeiros. Não houve diferença significativa nos pesos das mães à desmama, mas houve diferença entre o peso ao parto e à desmama . A suplementação materna e a idade de desmama, nas condições do experimento, não interferiram na capacidade reprodutiva das matrizes.
\end{abstract}

Palavras-chave: cordeiros superprecoces, desmama, ovinos, reprodução

\section{Effects of Age at Weaning and Feed Management on the Production of Super-Young Lambs}

\begin{abstract}
The objective of this experiment was to verify the effect of weaning age and ewe supplementation on the production of super-young lambs and on the reproductive cycle of dams. Sixty-six Hampshire Down ewes, ranging between 3 and 4 years of age, were kept with their lambs on grass pasture. All lambs were creep fed. The ewes were either supplemented $(n=34)$ or not $(n=32)$ during lactation. The lambs were randomly allocated to four treatments: T1 - weaned from supplemented dams at 34 days of age ( $\mathrm{n}=16$ ); T2 weaned from supplemented dams at 62 days $(n=18)$; T3 - weaned from not supplemented dams at 34 days $(n=16)$; T4 - weaned from not supplemented dams at 62 days $(\mathrm{n}=16)$. A 2 x 2 factorial arrangement was used in a randomized block design. Lambs from T2 and T4 showed higher weight gains than those weaned at days 34 (T1 and T3). Weight at day 62 was higher and slaughter age lower in lambs weaned from not supplemented mothers. Carcass yield and compactness index were higher in the lambs weaned at day 62 . Dam supplementation increased meat tenderness. No difference was observed in backfat thickness. No difference was observed in weight dams at weaning, but difference between body weight of dam at parturition and at weaning weight was observed. Neither dam supplementation nor lamb weaning age showed any effect on dam reproductive efficiency.
\end{abstract}

Key Words: super young lambs, weaning, sheep, reproduction

\section{Introdução}

A ovinocultura moderna tem se direcionado para a produção de carne que começa a ser mais aceita pelos grandes mercados consumidores do Brasil. No entanto, é importante salientar que esse mercado consumidor exige uma carne com excelência em qualidade e padronizada, tanto em tamanho como em maciez e teores de gordura. Esse tipo de produto somente pode ser obtido mediante $o$ abate de animais jovens e se pode esperar que o consumidor pague preços melhores por um produto mais nobre.

A estrutura fundiária dos Estados da Região Sudeste do Brasil não permite a implantação de uma ovinocultura de carne em escala, e por essa razão, as orientações técnicas recomendam sistemas de pro-

\footnotetext{
1 Parte da Dissertação de Mestrado do primeiro autor.

2 Mestrando do curso de Pós-Graduação em Zootecnia da FMVZ- UNESP-Botucatu.

3 Professores Assistentes Doutores do Departamento de Melhoramento Zootécnico e Nutrição Animal da FMVZ - UNESP- Botucatu.

E.mail:arrigoni@fca.unesp.br

4 Professor Titular do Departamento de Melhoramento Zootécnico e Nutrição Animal da FMVZ/UNESP/Botucatu.

5 Professor Assistente Doutor - Departamento de Química e Bioquímica do IB-UNESP-Botucatu.
} 
dução intensivos, normalmente feitos em regime de confinamento. Em contrapartida, deve-se considerar que os cordeiros apresentam imensa capacidade de crescimento nas primeiras semanas de vida, e esse potencial que não pode ser desprezado. As recomendações de desmama precoce objetivam a mais rápida entrada do cordeiro ao sistema de alimentação intensiva, mas impõem ao sistema de produção uma fase de recria, normalmente feita a pasto. Infere-se, portanto, que as técnicas de produção vigentes dirigem os recursos para a terminação do cordeiro, mas preterem o cordeiro enquanto lactente. Tal prática pode ser um contra-senso e se constituir em uma forma de subtilização do potencial de crescimento dos cordeiros novos.

Segundo o NRC (1985), a deposição de gordura em cordeiros implica em exigências energéticas aproximadamente três vezes maiores do que a necessária para o seu crescimento muscular. Vários trabalhos têm correlacionado o confinamento à gordura excessiva nas carcaças, o que, além de um fator de demérito ao gosto do consumidor, pode ser uma forma errônea de manipulação do crescimento.

$\mathrm{O}$ estudo do crescimento envolve um entendimento da magnitude e seqüência de deposição de tecidos em diferentes estádios de desenvolvimento (Rouse et al., 1970). Waghorn et al. (1990) postularam que a energia insuficientemente ingerida por cordeiros lactentes é a maior causa de repressão no seu crescimento. No entanto, pode-se inferir que, com pouca idade, dificilmente os cordeiros utilizariam a energia ingerida para produção de gordura.

A alternativa de fornecimento de concentrados a cordeiros, a partir de 15 dias de vida, pode complementar o fornecimento energético e protéico do leite materno que tende a diminuir com o avanço da lactação. A adoção de creep-feeding pode cumprir esse objetivo, sem onerar o custo de manutenção das ovelhas. A utilização de rações palatáveis no creep-feeding pode inclusive diminuir a intensidade de mamada dos cordeiros e, com isso, minimizar a demanda energética da lactação. Poupança energética nas ovelhas durante essa fase pode ser direcionada para novo ciclo reprodutivo do rebanho.

Essa proposta combina perfeitamente com as conclusões de Pollot \& Kilkenny (1994), de que um sistema racional de produção de carne deve envolver, não só o potencial de crescimento dos cordeiros, mas também a capacidade reprodutiva dos rebanhos que os originam. Conclui-se, portanto, que o maior aproveitamento da capacidade reprodutiva das ovelhas e da capacidade de crescimento de cordeiros lactentes, pode constituir uma combinação capaz de racionalizar um sistema produtivo como um todo.

Assim, o objetivo do presente trabalho foi verificar o efeito da suplementação das ovelhas sobre a época da desmama, na produção de cordeiros superprecoces e no ciclo reprodutivo da mãe.

\section{Material e Métodos}

O experimento foi conduzido na Fazenda Grama Roxa, no município de Avaré, Estado de São Paulo, entre os meses de dezembro de 1999 e março de 2000. O delineamento experimental adotado foi o de blocos ao acaso, com esquema fatorial ( $2 \times 2)$, (Snedecor \& Cochran, 1978), sendo o fator "D" a idade de desmama e fator "S", a suplementação ou não suplementação das ovelhas durante a lactação.

Foram utilizados 66 ovelhas adultas e 66 cordeiros da raça Hampshire Down, distribuídos em quatro tratamentos: T1 - Cordeiros desmamados aos 34 dias, com mães suplementadas; T2 - Cordeiros desmamados aos 62 dias, com mães suplementadas; T3 Cordeiros desmamados aos 34 dias, e mães não suplementadas; T4 - Cordeiros desmamados aos 62 dias, e mães não suplementadas.

Durante toda a gestação, as ovelhas foram mantidas em pastagens de coastcross (Cynodon dactylon), com acesso apenas a sal mineralizado.

Ao nascimento os cordeiros e ovelhas foram retirados do piquete de parição, pesados e marcados. As ovelhas paridas foram everminadas e permaneceram então no centro de manejo, acompanhadas dos cordeiros, por um período de três a cinco dias com feno e ração concentrada. Esse tempo foi considerado o suficiente para que os cordeiros recebessem o corte da cauda e a cura completa do umbigo. A diferença de idade dos 66 cordeiros utilizados no experimento foi de 15 dias, sendo o peso ao nascer em torno de 4,0 quilos.

As ovelhas e os cordeiros foram instalados, seqüencial e aleatoriamente, em dois piquetes contíguos, de mesmo tamanho, cultivados com coastcross (Cynodon dactylon), em uma taxa de lotação de 10 animais adultos com peso médio de $49,5 \mathrm{~kg}$ por hectare (equivalente a 1,1 UA/ha). Em um dos piquetes foram colocados cochos para fornecimento de concentrado às ovelhas. No segundo piquete, não foram colocados cochos para suplementação de ovelhas. Em ambos os piquetes, foram instaladas estru- 
turas de creep-feeding medindo $12 \mathrm{~m}^{2}$ cada uma, de modo que pudessem ser mudadas conforme o regime de rotação das pastagens. Nos primeiros dez dias em que os animais foram soltos na pastagem, os cordeiros foram recolhidos diariamente ao creep-feeding, onde ficaram retidos por um período de quatro horas com concentrado disponível. Esta prática foi necessária para indução do consumo da ração, e adaptação dos cordeiros ao cercado. A partir do $10 \underline{0}$ dia, não foi mais necessário tal procedimento.

As rações concentradas foram formuladas conforme as recomendações do NRC (1985). Para os cordeiros foram utilizadas duas rações: uma utilizada no creep-feeding e outra utilizada no confinamento, ambas com consumo ad-libitum. Trinta e duas ovelhas foram separadas aleatoriamente e colocadas em regime de suplementação com concentrados, nos cochos dispostos na pastagem. Para as ovelhas dos dois tratamentos suplementados (T1 e T2), o fornecimento foi restrito a $600 \mathrm{~g}$ de concentrado/ovelha/dia, equivalente a $1 \%$ de seu peso vivo médio. A suplementação das ovelhas dos tratamentos T1 e T2 permaneceu inalterada até o final do experimento, independentemente do fato de seus cordeiros terem sido desmamados aos 34 ou 62 dias. O restante do grupo de matrizes (34) permaneceu apenas em pastejo, sem suplementação.

Dessas rações, bem como da pastagem utilizada, foram retiradas amostras para análise, e os resultados estão expressos na Tabela 1.

Em todos os tratamentos, logo após o parto, as matrizes foram acompanhadas de rufiões para identificação dos cios. Além disso, esperou-se que pudessem provocar indução ao estro pelo efeito de macho (Folch et al., 1990). Foi considerado retorno, as ovelhas que tiveram marcação nítida na garupa. A avaliação foi feita pelo percentual de retorno ao cio entre tratamentos, dentro de um período máximo de 90 dias.

As desmamas foram efetuadas aos 34 e 62 dias de idade. Ao completarem 34 dias de vida, metade dos cordeiros das ovelhas suplementadas e das não suplementadas foi retirada dos piquetes e levados ao confinamento. $\mathrm{O}$ mesmo procedimento foi seguido para o tratamento com desmama feita aos 62 dias de idade.

$\mathrm{O}$ confinamento consistiu de uma estrutura fechada, com área de $120 \mathrm{~m}^{2}$, totalmente coberta. Nele foram utilizados 30 metros lineares de cochos de madeira. À ração de confinamento fornecida logo após a desmama foram adicionados duas gramas de Terramicina ${ }^{\circledR}$ pó solúvel $/ \mathrm{kg}$, durante quatro dias, como controle terapêutico de clostridioses. Após essa fase, foi utilizada a ração de confinamento sem a inclusão do antibiótico. Os animais permaneceram em confinamento até que atingissem o peso proposto de abate.

As pesagens dos cordeiros foram feitas ao nascimento, após a primeira mamada e semanalmente, até a data de desmame ou abate. Por ocasião do desmame, as ovelhas de todos os tratamentos também foram pesadas e tiveram os pesos anotados para posterior análise. O controle parasitológico foi feito por amostragem semanal em $10 \%$ das ovelhas e $10 \%$ dos cordeiros de todos os tratamentos. Foram everminadas as ovelhas e cordeiros dos grupos que ultrapassaram a contagem média de 500 o.p.g. (ovos/grama de fezes).

Os cordeiros que atingiram um mínimo de $28 \mathrm{~kg}$ de peso vivo foram considerados passíveis de abate. Esse peso foi estabelecido por otimizar as características quantitativas de carcaças de borregos Hampshire Down (Silva \& Pires, 2000). Previamente ao abate, os cordeiros foram submetidos a 12 horas de jejum de sólidos e pesados para cálculo do rendimento de carcaça quente.

Foram avaliadas ao abate as características de rendimento de carcaça quente $(\%)$, calculada pelo peso de carcaça quente dividida pelo peso vivo ao abate multiplicado por 100 eíndice de compacidade da carcaça $(\mathrm{kg} / \mathrm{cm})$, calculado pelo peso da carcaça fria, dividido pelo seu comprimento interno (Sañudo \& Sierra, 1986). O comprimento interno da carcaça é medido pela distância máxima entre o bordo anterior da sínfise ísquio-pubiana e o bordo anterior da primeira costela.

Foram escolhidas aleatoriamente 30 carcaças de machos de onde se retirou, na metade esquerda da carcaça, amostras do músculo longissimus minor. Essas amostras foram etiquetadas, acondicionadas em sacos plásticos e congeladas para posterior análise de maciez, teste Shear Force, medido por intermédio de um equipamento Warner-Bratzler. O preparo de amostras para análise de maciez foi o recomendado pelo procedimento de Wheller et al. (1995). Por ocasião do abate, foram feitas as análises de gordura de cobertura, utilizando-se um método indireto sob avaliação visual. Esse método constou de uma escala hedônica de cinco pontos, sendo " 1 " para carcaças excessivamente magras e "5" para as excessivamente gordas (Summers et al., 1978).

Os dados obtidos foram submetidos à análise de variância (ANAVA) e as médias, comparadas pelo teste Tukey, a 5\% de probabilidade. Os resultados foram analisados por intermédio do programa computacional SAS (SAS, 1989). 
Tabela 1 - Formulação e composição química das rações experimentais e pastagem Table 1 - Formulation and chemical composition of the experimental rations and pasture

\begin{tabular}{|c|c|c|c|c|}
\hline $\begin{array}{l}\text { Alimento } \\
\text { Feed }\end{array}$ & $\begin{array}{c}\text { Cordeiros em } \\
\text { creep-feeding } \\
\text { Lamb } \\
\text { creep-feeding }\end{array}$ & $\begin{array}{c}\text { Cordeiros em } \\
\text { confinamento } \\
\text { Lamb } \\
\text { feedlot }\end{array}$ & $\begin{array}{l}\text { Ovelhas em } \\
\text { manutenção } \\
\text { Ewe } \\
\text { maintenance }\end{array}$ & $\begin{array}{l}\text { Pastagem } \\
\text { Pasture }\end{array}$ \\
\hline $\begin{array}{l}\text { Milho moído }(\%) \\
\text { Cracked corn }\end{array}$ & 50,00 & 56,60 & 63,50 & - \\
\hline $\begin{array}{l}\text { Farelo de soja }(\%) \\
\text { Soybean meal }\end{array}$ & 24,00 & 20,00 & 20,00 & - \\
\hline $\begin{array}{l}\text { Levedura }(\%) \\
\text { Brewer }\end{array}$ & 2,50 & - & - & - \\
\hline $\begin{array}{l}\text { DL-metionina }(\%) \\
\text { DL-methionine }\end{array}$ & 0,10 & - & - & - \\
\hline $\begin{array}{l}\text { L-Lisina }(\%) \\
\text { L-Lysine }\end{array}$ & 0,30 & - & - & - \\
\hline $\begin{array}{l}\text { Minerais }{ }^{1}(\%) \\
\text { Minerals }\end{array}$ & 1,00 & 1,00 & 1,00 & - \\
\hline $\begin{array}{l}\text { Farelo de trigo }(\%) \\
\text { Wheat meal }\end{array}$ & 11,60 & 4,20 & 15,50 & - \\
\hline $\begin{array}{l}\text { Calcita }(\%) \\
\text { Limestone }\end{array}$ & 0,50 & 0,30 & 0,50 & - \\
\hline $\begin{array}{l}\text { Rumensin }{ }^{\circledR}(\mathrm{ppm}) \\
\text { Rumensin }\end{array}$ & 30 & 30 & - & - \\
\hline $\begin{array}{l}\text { Açúcar }(\%) \\
\text { Sugar }\end{array}$ & 2,00 & - & - & - \\
\hline $\begin{array}{l}\text { Feno gramínea }(\%) \\
\text { Grass hay }\end{array}$ & - & 2,00 & - & - \\
\hline $\begin{array}{l}\text { Proteína bruta }(\%) \\
\text { Crude protein }\end{array}$ & 17,45 & 14,55 & 15,53 & 12,97 \\
\hline $\begin{array}{l}\text { Matéria seca }(\%) \\
\text { Dry mater }\end{array}$ & 89,90 & 88,80 & 88,88 & 34,71 \\
\hline $\begin{array}{l}\text { Ext. não nitrogenado }(\%) \\
\text { Free nitrogen extract }\end{array}$ & 69,77 & 68,21 & 62,05 & 66,31 \\
\hline $\begin{array}{l}\text { Extrato etéreo }(\%) \\
\text { Ether extract }\end{array}$ & 4,44 & 4,71 & 4,17 & 3,86 \\
\hline $\begin{array}{l}\text { Fibra bruta }(\%) \\
\text { Crude fiber }\end{array}$ & 3,75 & 8,39 & 3,93 & 27,13 \\
\hline $\begin{array}{l}\text { NDT }(\%)(\text { estimado }) \\
T D N\end{array}$ & 77,58 & 68,21 & 62,05 & 62,30 \\
\hline $\begin{array}{l}\text { Fibra detergente ácido (\%) } \\
\text { Acid detergent fiber }\end{array}$ & 5,68 & 12,45 & 5,68 & 35,79 \\
\hline $\begin{array}{l}\text { Fibra detergente neutro }(\%) \\
\text { Neutral detergent fiber }\end{array}$ & 17,56 & 29,40 & 21,95 & 73,67 \\
\hline
\end{tabular}




\section{Resultados e Discussão}

O sistema de produção intensivo propõe a utilização do creep-feeding para aumentar o ganho de peso em cordeiros. Esse aumento no desenvolvimento dos cordeiros durante a fase de lactente é necessário para se fazer uma desmama mais precoce do que a convencional, ao redor de quarenta e cinco dias. É necessário que os cordeiros estejam adaptados ao consumo de alimentos sólidos e apresentem desenvolvimento mínimo capaz de assegurar a continuidade do seu crescimento. Os resultados da utilização do creepfeeding nos moldes do presente experimento, onde se prolongou a sua utilização, estão apresentados nas
Tabelas 2 e 3. Houve efeito significativo $(\mathrm{P}<0,05)$ da idade à desmama no ganho de peso diário dos cordeiros, independentes da suplementação das matrizes.

Esses resultados mostraram ganho de peso médio diário de $365 \mathrm{~g}$ nos animais dos grupos desmamados tardiamente contra $319 \mathrm{~g}$ dos animais que foram desmamados aos 34 dias, independentemente da suplementação das matrizes. Houve efeito significativo da suplementação das ovelhas $(\mathrm{P}<0,05)$ no ganho de peso diário dos cordeiros, independentemente da idade à desmama (Tabela 3). A média de ganho de peso diário nos cordeiros cujas mães foram suplementadas (T1 e T2) foi de 330,5 g contra 354,5 $\mathrm{g}$ dos tratamentos cujas mães não tiveram acesso a concentrados (T3 e T4).

Tabela 2 - Médias e desvios-padrão do desempenho dos cordeiros em quatro diferentes tratamentos

Table 2 - Means and standard deviations of performance in lambs of four different treatments

\begin{tabular}{|c|c|c|c|c|}
\hline \multirow{4}{*}{$\begin{array}{l}\text { Tratamento } \\
\text { Treatment }\end{array}$} & \multirow{2}{*}{\multicolumn{2}{|c|}{$\begin{array}{c}\text { Idade à desmama } \\
\text { Weaning age }\end{array}$}} & \multirow{2}{*}{\multicolumn{2}{|c|}{$\begin{array}{c}\text { Suplementação das ovelhas } \\
\text { Supplemented ewes }\end{array}$}} \\
\hline & & & & \\
\hline & \multirow{2}{*}{$\begin{array}{l}34 \text { Dias } \\
34 \text { Days }\end{array}$} & \multirow{2}{*}{$\begin{array}{l}62 \text { Dias } \\
62 \text { Days }\end{array}$} & \multirow{2}{*}{$\begin{array}{l}\text { Suplementadas } \\
\text { Supplemented }\end{array}$} & \multirow{2}{*}{$\begin{array}{c}\text { Não Suplementadas } \\
\text { Not Supplemented }\end{array}$} \\
\hline & & & & \\
\hline Peso ao nascimento $(\mathrm{kg})^{1}$ & $4,78 \pm 1,14$ & $4,51 \pm 1,09$ & $4,70 \pm 1,07$ & $4,60 \pm 1,15$ \\
\hline \multicolumn{5}{|l|}{ Birth weight ( $k g)$} \\
\hline Peso aos 34 dias de desmama ${ }^{1}$ & $14,80 \pm 2,80^{b}$ & $17,53 \pm 2,59^{\mathrm{a}}$ & $16,62 \pm 2,93^{\mathrm{a}}$ & $15,71 \pm 2,46^{\mathrm{a}}$ \\
\hline \multicolumn{5}{|l|}{ Weaning weight at 34 days } \\
\hline Peso aos 62 dias de desmama ${ }^{1}$ & $23,54 \pm 3,25^{b}$ & $27,72 \pm 2,40^{\mathrm{a}}$ & $24,37 \pm 3,30^{\mathrm{b}}$ & $26,23 \pm 2,35^{\mathrm{a}}$ \\
\hline Weaning weight at 62 days & & & & \\
\hline
\end{tabular}

${ }_{1}^{1}$ Médias seguidas de letras diferentes diferem significativamente $(\mathrm{P}<.05)$ pelo teste Tukey.

${ }^{1}$ Means followed by different letters significantly differ $(P<.05)$ by Tukey test.

Tabela 3 - Médias e desvios-padrão do ganho de peso diário (kg) e idade ao abate (dias) de cordeiros em quatro diferentes tratamentos

Table 3 - Means and standard deviations of average daily gain $(\mathrm{kg})$ and age at slaughter (days) in lambs of four different treatments

\begin{tabular}{|c|c|c|c|c|}
\hline \multirow[t]{2}{*}{$\begin{array}{l}\text { Tratamento } \\
\text { Treatment }\end{array}$} & \multicolumn{2}{|c|}{$\begin{array}{l}\text { Idade à desmama } \\
\text { Weaning age }\end{array}$} & \multicolumn{2}{|c|}{$\begin{array}{l}\text { Suplementação das ovelhas } \\
\text { Supplemented ewes }\end{array}$} \\
\hline & $\begin{array}{l}34 \text { Dias } \\
34 \text { Days }\end{array}$ & $\begin{array}{l}62 \text { Dias } \\
62 \text { Days }\end{array}$ & $\begin{array}{l}\text { Suplementadas } \\
\text { Supplemented }\end{array}$ & $\begin{array}{l}\text { Não Suplementadas } \\
\text { Not Supplemented }\end{array}$ \\
\hline $\begin{array}{l}\text { Ganho de peso vivo diário }(\mathrm{kg})^{1} \\
\text { Average daily gain }(\mathrm{kg})^{1}\end{array}$ & $0,319 \pm 0,03^{b}$ & $0,365 \pm 0,03^{\mathrm{a}}$ & $0,331 \pm 0,03^{b}$ & $0,355 \pm 0,02^{\mathrm{a}}$ \\
\hline $\begin{array}{l}\text { Idade ao abate }(\text { dias })^{1} \\
\text { Age at slaughter(days) }{ }^{1}\end{array}$ & $73,22 \pm 7,61^{\mathrm{a}}$ & $64,81 \pm 6,45^{\mathrm{b}}$ & $71,38 \pm 9,16^{\mathrm{a}}$ & $66,65 \pm 4,89^{b}$ \\
\hline
\end{tabular}

${ }^{1}$ Médias seguidas de letras minúsculas diferentes nas linhas diferem significativamente entre si pelo teste de Tukey $(\mathrm{P}<0,05)$, quanto à idade à desmama.

${ }^{1}$ Means followed by different lower case letters in the collumns differ significantly by Tukey test $(P<.05)$, by weaning age. 
Houve interação significativa $(\mathrm{P}<0,05)$ entre a suplementação materna e idade a desmama, no ganho de peso diário. As diferenças significativas $(\mathrm{P}<0,05)$ no ganho de peso diário dos tratamentos refletiram na idade de abate aos 28 quilos propostos.

A idade ao abate foi influenciada significativamente pela desmama $(\mathrm{P}<0,05)$ e pela suplementação materna $(\mathrm{P}<0,05)$ (Tabela 3). Não houve interação entre as variáveis para idade ao abate. $\mathrm{O}$ peso à desmama aos 34 dias não apresentou diferença significativa $(P>0,05)$ entre a suplementação e não suplementação materna, mas houve diferença significativa $(\mathrm{P}<0,05)$ na pesagem aos 34 dias entre os tratamentos desmamados aos 34 e 62 dias no peso equivalente.

Houve diferença significativa $(\mathrm{P}<0,05)$ entre os tratamentos para peso à desmama aos 62 dias, idade à desmama e suplementação materna.

Quanto à variável idade à desmama, observou-se que a desmama aos 34 dias, a chamada desmama precoce trouxe, nas condições do experimento, conseqüências no desempenho dos cordeiros, quando observado o período inteiro de seu desenvolvimento. Os cordeiros desmamados aos 62 dias apresentaram ganho de peso diário mais regular, enquanto os cordeiros desmamados precocemente (32 dias) apresentaram depressão no ganho de peso diário, quando entraram para o sistema de confinamento. Resultados semelhantes foram obtidos por Peeters et al. (1995), os quais concluíram que a desmama precoce pode trazer problemas no ganho de peso futuro dos cordeiros. Jordon \& Marten (1968) observaram também que a antecipação da desmama em cordeiros causou depressão no seu ganho de peso durante duas semanas. Os autores concluíram que os cordeiros diminuíram a ingestão de alimentos, devido à ausência das mães. Neste experimento, os cordeiros foram imediatamente confinados após a desmama, e não pôde ser observada depressão no seu consumo diário de ração. Não obstante, a diferença significativamente inferior observada no peso dos cordeiros desmamados aos 34 dias, em relação aos cordeiros não desmamados (T2 e T4), poderia resultar em semelhantes idades ao abate para os quatro tratamentos (Tabela 3). Essas suposições se embasam nos resultados observados por Jenkins (1986) de que a desmama precoce promove menor peso à desmama em relação à desmama tardia, mas que os cordeiros obtêm melhor eficiência de ganho de peso. Manso et al. (1998) também observaram que mudanças anatômicas do trato gastrintestinal decorrentes da dieta causaram aumentos na digestibilidade da proteína e matéria orgânica, o que representou melhora na conversão alimentar. Os mesmos resultados foram obtidos por Notter et al. (1991), que observaram aumento no ganho de peso em cordeiros desmamados e confinados, quando comparados a cordeiros que permaneceram em pastagem. No entanto, os resultados deste experimento demonstraram justamente o oposto. Houve aumento significativo na idade ao abate, quando os cordeiros foram desmamados precocemente, independentemente da suplementação das ovelhas. Tal fato pode ser explicado pela adaptação ao sistema de confinamento, e pelo próprio desenvolvimento fisiológico dos cordeiros. Attaix \& Meslin (1991) relataram que cordeiros desmamados muito cedo não têm aparato enzimático e digestivo para absorverem altos níveis de carboidratos. Esperar-se-ia que os cordeiros que permaneceram na pastagem com as mães apresentassem menor ganho de peso diário, quando comparados aos cordeiros desmamados e imediatamente confinados. No entanto, apesar da situação precária das pastagens e da suplementação das matrizes, os cordeiros desmamados aos 62 dias não necessitaram de confinamento para atingirem o peso de abate mínimo estipulado. Esse resultado é bastante importante, por representar economia substancial de insumos e cuidados dentro do sistema de produção proposto.

Quanto à suplementação das matrizes, Folman et al . (1966b) encontraram altas correlações entre consumo de leite e ganho de peso em cordeiros até a $8^{\mathrm{a}}$ semana de vida. Embora esta correlação declinasse após essa fase, ela ainda estaria dentro do período experimental proposto para este trabalho e pode explicar o fato de os cordeiros não desmamados apresentarem melhores ganhos diários e menor idade ao abate.

Para concordância dos resultados do presente experimento com aqueles obtidos por Folman et al (1966a), esperar-se-ia que os tratamentos nos quais as mães foram suplementadas apresentassem significativa diferença no desempenho dos cordeiros, em decorrência da suplementação das matrizes, o que provavelmente elevou sua produção de leite.

No entanto, os resultados do presente experimento são completamente opostos, observando-se maior do peso dos cordeiros cujas mães não foram suplementadas.

O consumo de alimentos no cocho é inversamente proporcional à quantidade de leite ingerido (NRC, 1985; Foot, 1972) ou ainda que está condicionado à

R. Bras. Zootec., v.32, n.6, p.1969-1980, 2003 (Supl. 2) 
supressão da amamentação constante (Folman et al., 1966b). Um cordeiro em crescimento tem as necessidades de ingestão de alimento crescente, correspondida por aumentos na ingestão de forragem ou outros alimentos (Ramsey et al., 1994) e o ganho de peso é influenciado pelo consumo de alimentos sólidos durante a amamentação (Hatfield et al., 1995). Pôde-se esperar, portanto, que os cordeiros que tiveram acesso à maior quantidade de leite, não consumiram quantidade necessária de concentrado no creepfeeding. Wilson et al. (1971) também concluíram que aumentos na ingestão de energia por ovelhas lactantes tenderam a ser inversamente proporcionais à eficiência no ganho de peso de cordeiros. O rúmen adquire funcionalidade a partir de 14 dias de vida (Susin, 1996) e necessita de alimentos sólidos para o desenvolvimento de suas papilas e conseqüentemente sua funcionalidade. O melhor desempenho no ganho de peso dos cordeiros desmamados aos 62 dias de idades com ovelhas não suplementadas (Tabela 3) deve-se, provavelmente, à combinação desses fatores. Aliado a isso, o consumo de alimentos concentrados aumenta rapidamente a população microbiana do rúmem e, assim, sua eficiência.

Foi observada interação significativa $(\mathrm{P}<0,05)$ entre idade à desmama e suplementação materna para o ganho de peso diário. Esses resultados explicam os pesos na fase de abate, independentemente de os cordeiros terem as mães suplementadas ou não. $\mathrm{O}$ peso mais alto $(\mathrm{P}<0,05)$ dos cordeiros desmama- dos aos 62 dias com ovelhas suplementadas ou não (T2 e T4) observado aos 34 dias não pôde ser explicado.

As avaliações e os resultados de peso vivo ao abate, peso de carcaça quente e rendimento de carcaça estão mostrados na Tabela 4.

$O$ peso vivo ao abate não diferiu significativamente entre os tratamentos $(\mathrm{P}>0,05)$, em decorrência de ter sido fixado o peso mínimo de 28 quilos. Embora não significativo, os cordeiros desmamados aos 34 dias de dias com ovelhas suplementadas foram abatidos com peso um pouco maior, devido ao maior tempo que permaneceram no confinamento. Todavia, o peso mínimo de 28 quilos foi observado e considerado para análise.

O peso de carcaça tomado logo após o abate não apresentou diferença significativa $(\mathrm{P}>0,05)$ entre os cordeiros desmamados aos 34 dias de idade com ovelhas suplementadas e desmamados aos 62 dias de idade com ovelhas suplementadas ou não, sendo significativamente $(\mathrm{P}<0,05)$ superior nas carcaças de cordeiros desmamados aos 62 dias de idade com ovelhas não suplementadas. Observa-se que, a despeito de não existir diferença entre os pesos vivos ao abate, o peso de carcaça quente apresentou diferença significativa $(\mathrm{P}<0,05)$. Esse resultado pôde ser explicado pelos rendimentos de carcaça dos quatro tratamentos (Tabela 4).

Houve diferença significativa $(\mathrm{P}<0,05)$ entre os tratamentos quanto a idade à desmama, para rendi-

Tabela 4 - Médias ${ }^{1}$ e desvios-padrão dos pesos vivos, peso de carcaça e rendimento de carcaça de cordeiros de quatro diferentes tratamentos

Table 4 - Means ${ }^{1}$ and standard deviations of live weight, carcass weight and carcass yield in lambs of four different treatments

\begin{tabular}{|c|c|c|c|c|}
\hline \multirow{3}{*}{$\begin{array}{l}\text { Tratamento } \\
\text { Treatment }\end{array}$} & \multirow{2}{*}{\multicolumn{2}{|c|}{$\begin{array}{c}\text { Idade à desmama } \\
\text { Weaning age }\end{array}$}} & \multirow{2}{*}{\multicolumn{2}{|c|}{$\begin{array}{l}\text { Suplementação das ovelhas } \\
\text { Supplemented ewes }\end{array}$}} \\
\hline & & & & \\
\hline & $\begin{array}{l}34 \text { Dias } \\
34 \text { Days }\end{array}$ & $\begin{array}{l}62 \text { Dias } \\
62 \text { Days }\end{array}$ & $\begin{array}{l}\text { Suplementadas } \\
\text { Supplemented }\end{array}$ & $\begin{array}{l}\text { Não Suplementadas } \\
\text { Not Supplemented }\end{array}$ \\
\hline $\begin{array}{l}\text { Peso vivo }(\mathrm{kg})^{2} \\
\text { Live weight }(\mathrm{kg})\end{array}$ & $29,00 \pm 1,67$ & $28,85 \pm 2,64$ & $28,32 \pm 2,59$ & $28,93 \pm 1,72$ \\
\hline $\begin{array}{l}\text { Peso de carcaça }(\mathrm{kg})^{3} \\
\text { Carcass weight }\end{array}$ & $13,26 \pm 1,09^{b}$ & $14,22 \pm 1,27^{\mathrm{a}}$ & $13,60 \pm 1,38^{\mathrm{b}}$ & $13,88 \pm 0,99^{b}$ \\
\hline $\begin{array}{l}\text { Rendimento de carcaça (\%) } \\
\text { Carcass yield (\%) }\end{array}$ & $45,68 \pm 1,86^{b}$ & $50,40 \pm 1,27^{\mathrm{a}}$ & $48,09 \pm 1,94^{b}$ & $47,99 \pm 1,18^{b}$ \\
\hline
\end{tabular}

${ }^{1}$ Médias seguidas de letras diferentes diferem significativamente $(\mathrm{P}<.05)$ pelo teste Tukey.

${ }_{1}^{1}$ Means followed by different letters significantly differ $(P<.05)$ by Tukey test.

2 Referente ao peso vivo após jejum de sólidos por 12 horas.

2 Refers to the live weight after 12 hours solid fasting.

${ }^{3}$ Referente ao peso da carcaça quente.

${ }^{3}$ Refers to the hot carcass weight. 
mento de carcaça. Os resultados indicam que a ingestão de alimentos no confinamento causou maior desenvolvimento do rúmem e dos demais componentes do trato gastrintestinal. Esse fenômeno ocorreu com a desmama precoce e pode-se supor que o desenvolvimento mais lento foi devido ao crescimento dos componentes não carcaça. Essa conclusão pode ser sustentada por Manso et al. (1998), quando concluíram que o tratamento com alta proteína na pós-desmama aumentou a proporção do retículorúmen no peso do trato gastrintestinal de cordeiros. Essa dieta também causou aumento na ingestão de alimentos sólidos. Infere-se, portanto, que a dieta na fase pré-desmama altera o comportamento alimentar dos cordeiros quando desmamados e o aumento da ingestão de matéria seca causa prejuízos no rendimento de carcaça. Os resultados de rendimento de carcaça são de grande importância econômica. Melhorias no seu rendimento possibilitam o abate de cordeiros com menor peso vivo sem prejuízo no peso de carcaças. Além disso, a menor idade ao abate equivale a carcaças de melhor qualidade, senão pela menor deposição de gordura, pela maior relação carne e ossos, característica que pode ser medida pelo índice de compacidade.

Observa-se que os cordeiros, independentemente da idade à desmama e da suplementação das matrizes, não apresentaram diferenças significativas entre os quatro tratamentos, quanto ao grau de gordura. Esse índice reflete a gordura de cobertura das carcaças, e foram avaliadas de forma visual em uma escala variando de 1 a 5 , para carcaças mais magras e mais gordas, respectivamente. Esses resultados são mostrados na Tabela 5.

Os cordeiros desmamados aos 34 dias (tratamentos T1 e T3) foram alimentados no mínimo 26 dias em confinamento antes de serem abatidos. A dieta utilizada no confinamento desse experimento previu uma alta densidade energética e protéica para aceleração do crescimento dos cordeiros desmamados. Além disso, é importante ressaltar o contraste entre a dieta do confinamento e a pastagem em que estavam colocados os cordeiros. Esperava-se que os animais desmamados aos 34 dias obtivessem índices mais elevados de gordura de cobertura nas carcaças do que os animais que foram mantidos em pastagem. Esses resultados não concordam com o esperado por inúmeros autores (Ely et al., 1979; Crouse et al., 1981; Arnold \& Meyer, 1988; Waghorn et al., 1990; Blackburn et al., 1991; Murphy et al., 1994) que relataram excessiva deposição de gordura subcutânea em cordeiros submetidos à alimentação intensiva no confinamento. Não concordaram tampouco com as conclusões de Arnold \& Meyer (1988) de que cordeiros terminados à base de forragem apresentaram cortes menos gordurosos do que animais confinados.

\begin{tabular}{|c|c|c|c|c|}
\hline \multirow{3}{*}{$\begin{array}{l}\text { Tratamento } \\
\text { Treatment }\end{array}$} & \multirow{2}{*}{\multicolumn{2}{|c|}{$\begin{array}{c}\text { Idade à desmama } \\
\text { Weaning age }\end{array}$}} & \multirow{2}{*}{\multicolumn{2}{|c|}{$\begin{array}{l}\text { Suplementação das ovelhas } \\
\text { Supplemented ewes }\end{array}$}} \\
\hline & & & & \\
\hline & $\begin{array}{l}34 \text { Dias } \\
34 \text { Days }\end{array}$ & $\begin{array}{l}62 \text { Dias } \\
62 \text { Days }\end{array}$ & $\begin{array}{l}\text { Suplementadas } \\
\text { Supplemented }\end{array}$ & $\begin{array}{l}\text { Não Suplementadas } \\
\text { Not Supplemented }\end{array}$ \\
\hline $\begin{array}{l}\text { Comprimento interno } \\
\text { de carcaça }(\mathrm{cm}) \\
\text { Internal carcass lenght }(\mathrm{cm})\end{array}$ & $56,26 \pm 2,07$ & $53,85 \pm 3,4$ & $53,9 \pm 3,27$ & $56,21 \pm 2,79$ \\
\hline $\begin{array}{l}\text { Grau de acabamento } \\
\text { Carcass fatness }^{2}\end{array}$ & $3,7 \pm 0,9$ & $3,62 \pm 0,63$ & $3,60 \pm 0,53$ & $3,73 \pm 0,50$ \\
\hline $\begin{array}{l}\text { Indice de compacidade } \\
(\mathrm{kg} / \mathrm{cm})^{3} \\
\text { Compactness index }(\mathrm{kg} / \mathrm{cm})^{3}\end{array}$ & $0,24 \pm 0,02^{b}$ & $0,27 \pm 0,02^{\mathrm{a}}$ & $0,26 \pm 0,02^{\mathrm{a}}$ & $0,25 \pm 0,01^{\mathrm{a}}$ \\
\hline
\end{tabular}

R. Bras. Zootec., v.32, n.6, p.1969-1980, 2003 (Supl. 2) 
Neste experimento, os resultados obtidos não mostraram diferenças significativas $(\mathrm{P}>0,05)$ entre os quatro tratamentos. Assim, esses resultados podem ser explicados pela idade com que os cordeiros foram abatidos. O fato de serem animais muito jovens (superprecoces) não permitiu diferenças de deposição de gordura entre os tratamentos, o que corrobora as conclusões de Arana et al. (1998) e Rattray et al. (1974), de que a hipertrofia e hiperplasia dos adipócitos, somadas à ação de enzimas ligadas ao processo de engorda, acarreta aumento do percentual das gorduras perirenal e subcutânea em cordeiros. Segundo os autores, esse aumento de gordura está relacionado principalmente ao aumento de idade, já que observaram maior deposição de gordura entre 89 e 120 dias de vida. Em todos os grupos deste experimento, os cordeiros foram abatidos antes da idade esperada por Arana et al. (1998) e Rattray et al. (1974), o que certamente explica as semelhanças na quantidade de gordura de cobertura, independentemente de diferentes níveis de ingestão de concentrados.

$O$ peso de abate também poderia ser um fator de discussão para o grau de acabamento. $\mathrm{O}$ peso ao abate dos cordeiros deste experimento foi de $28 \mathrm{~kg}$, portanto, menor que peso relatado por Rouse et al. (1970). Esses autores, ao estudarem a deposição dos diferentes tecidos relativos ao crescimento, concluíram que, a partir de $32 \mathrm{~kg}$, houve acentuado desenvolvimento no tecido adiposo em carcaças de cordeiros de corte.

Os tratamentos com desmama precoce (aos 34 dias de idade) apresentaram índices de compacidade significativamente menores $(\mathrm{P}<0,05)$, quando comparados aos de desmama tardia (Tabela 5). O índice de compacidade reflete a relação entre peso da carcaça e seu comprimento interno. Este apresentou diferenças significativas $(\mathrm{P}<0,05)$, devido à suplementação das matrizes, somente entre os cordeiros desmamados aos 34 e 62 dias de idade com ovelhas suplementadas e houve interação $(\mathrm{P}<0,05)$ entre as variáveis idade à desmama e suplementação materna. Os animais desmamados tardiamente e que não necessitaram de confinamento, apresentaram densidade muscular significativamente mais alta, com cerca de $0,270 \mathrm{~kg} / \mathrm{cm}$ de carne de carcaça, contra apenas $0,235 \mathrm{~kg} / \mathrm{cm}$ nas carcaças dos animais desmamados aos 34 dias, independentemente da suplementação materna. No entanto, não houve diferenças correspondentes no peso vivo e comprimento interno das carcaças. Dessa forma, pode-se inferir que a diferença existente no índice de compacidade entre os tratamentos, talvez, seja explicada somente pelas diferenças no peso das carcaças. Mais importante ainda, pode-se inferir, à vista de tais resultados, que não houve diferenças no crescimento ósseo propriamente dito e os índices de compacidade desiguais foram devidos a uma diferença na deposição muscular entre os cordeiros estudados. O resultado prático dessa sensível melhora é a de retalhamento da carcaça, possibilitando cortes comerciais mais rentáveis. O resultado obtido nas carcaças dos animais desmamados aos 62 dias de idade com ovelhas suplementadas ou não possibilitam maior utilização para vendas de carne ovina em cortes.

Os resultados do presente experimento mostraram melhora significativa $(\mathrm{P}<0,05)$ na maciez da carne de cordeiros cujas mães foram suplementadas (T1 e T2), independentemente da idade à desmama (Tabela 6), no entanto, esses dados não puderam ser explicados.

Summers et al. (1978) concluíram que a utilização de dietas altas em concentrados melhorou a maciez da carne de cordeiros, mas os resultados obtidos poderiam ser explicados somente para os cordeiros desmamados aos 34 dias de idade com ovelhas suplementadas que foram confinados por um período grande de tempo, uma vez que os animais desmamados aos 34 dias de idade com ovelhas não suplementadas não apresentaram melhora.

Os resultados de análise de maciez mostraram resultados mais baixos do que os obtidos por Summers et al. (1978), mas essa diferença pode ser justificada pela utilização do músculo Longissimus minor, sendo que os autores utilizaram o Longissimus dorsi em seu trabalho.

O fato das ovelhas serem alimentadas com rações concentradas não constituiu, nas condições do presente experimento, uma explicação isolada, se considerado somente o ganho de peso dos cordeiros. $\mathrm{O}$ aspecto reprodutivo, também objeto do presente experimento, foi mensurado. Segundo o NRC (1985), as exigências nutricionais das ovelhas durante a fase de lactação são extremamente aumentadas, e a sua manutenção em pastagem não consegue suprir o aumento da demanda energética e protéica da lactação. Como consequiência, pode-se observar perda acentuada de peso, no decorrer de lactações prolongadas (Notter \& McClaugherty,1991). Os resultados experimentais obtidos para os diferentes tratamentos das ovelhas estão expressos na Tabela 7. 
Os trabalhos consultados indicam a possibilidade de ocorrência de cios férteis num período de pósparto recente. Wallace et al. (1989), trabalhando com ovelhas induzidas, concluíram que as gonadotrofinas não foram fatores limitantes à prenhez de ovelhas lactantes até 42 dias após o parto. Fogarty et al. (1992) postularam que não há interferência da intensidade da mamada na atividade éstrica de ovelhas e que o fotoperíodo é o principal responsável pela sasonalidade reprodutiva dos ovinos (Chemineau et al., 1992; Mandiki et al., 1990). No entanto, Mitchell et al. (1998) concluíram que entre os fatores inibidores da liberação de LH (hormônio luteinizante) após parto, se inclui a amamentação associada à demanda metabólica da lactação, nutrição inadequada e/ou condição corporal precária.

No presente experimento, constatou-se que o peso corporal não foi significativamente diferente $(\mathrm{P}>0,05)$ no peso à desmama, independentemente dos tratamentos. No entanto, as diferenças entre peso ao parto e peso à desmama foram significativamente diferentes $(\mathrm{P}<0,05)$ para o fator idade à desmama $\mathrm{e}$ para o fator suplementação $(\mathrm{P}<0,05)$. Foi observada interação significativa $(\mathrm{P}<0,05)$ entre idade à desmama e suplementação das ovelhas.

O MLC (1981), citado por Folch et al. (1991), relata que escore corporal de ovelhas situado em torno de " 3 " (em uma escala de "1" a "5") é suficiente para sustentar aumentos reprodutivos do rebanho. Mitchell et al. (1998) concluíram que, em ovelhas paridas no momento normal, a sazonalidade possibilitou o ressurgimento de estros pós-parto. Os resultados obtidos nesta pesquisa mostram que a suplementação dos cordeiros em sistema de creep-

Tabela 6 - Médias e desvios-padrão de maciez de carne de cordeiros de quatro diferentes tratamentos: teste Shear-force medido em um equipamento Warner-Bratzler

Table 6 - Means and standard deviations of meat tenderness of lambs in four different treatments. Shear Force test measured in a Warner-Bratzler equipment

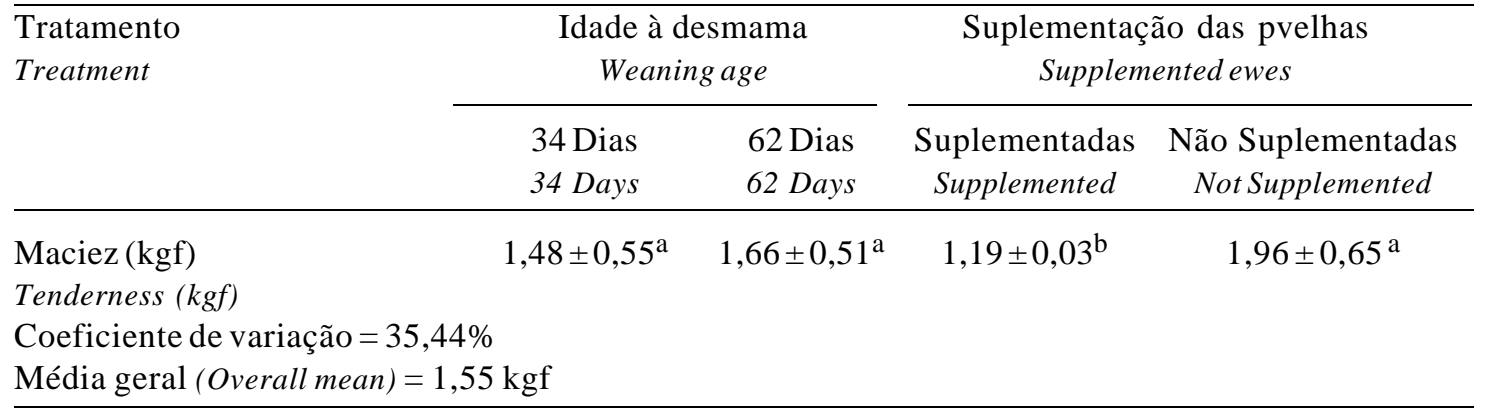

1 Médias seguidas de letras diferentes diferem significativamente $(P<.05)$ pelo teste Tukey.

${ }_{1}^{1}$ Means followed by different letters significantly differ $(P<.05)$ by Tukey test.

Tabela 7 - Médias e desvios-padrão do peso de ovelhas $(\mathrm{kg})$ ao parto e à desmama em quatro diferentes tratamentos

Table 7 - Mean and standard deviations of weight at parturition and weight at weaning of ewes in four different treatments

\begin{tabular}{lcccc}
\hline & $\begin{array}{c}\text { 34 Dias } \\
\text { 34 Days }\end{array}$ & $\begin{array}{c}\text { 62 Dias } \\
62 \text { Days }\end{array}$ & $\begin{array}{c}\text { Suplementadas } \\
\text { Supplemented }\end{array}$ & $\begin{array}{c}\text { Não Suplementadas } \\
\text { Not Supplemented }\end{array}$ \\
\hline $\begin{array}{l}\text { Peso ao parto } \\
\text { Parturition weight }^{1}\end{array}$ & $49,17 \pm 3,11$ & $49,82 \pm 3,07$ & $49,00 \pm 3,11$ & $50,04 \pm 2,89$ \\
Peso à desmama $^{1}$ & $47,95 \pm 3,07$ & $47,48 \pm 3,09$ & $47,94 \pm 2,92$ & $47,49 \pm 3,24$ \\
Weaning weight $^{1}$ & $1,27 \pm 1,00^{\mathrm{b}}$ & $2,37 \pm 1,32^{\mathrm{a}}$ & $1,05 \pm 1,36^{\mathrm{b}}$ & $2,59 \pm 0,99^{\mathrm{a}}$ \\
Diferença $^{2}$ & & & \\
Difference $^{2}$ & & & & \\
\hline
\end{tabular}

${ }^{1}$ Médias seguidas de letras diferentes diferem significativamente $(\mathrm{P}<.05)$ pelo teste Tukey.

${ }^{2}$ Calculada pelo peso ao parto - peso à desmama (em $\left.\mathrm{kg}\right)$.

${ }^{1}$ Means followed by different letters significantly differ $(P<.05)$ by Tukey test.

${ }^{2}$ Calculated by parturition weight - weaning weight $(\mathrm{kg})$. 
feeding aparentemente não refletiu perdas de peso corporal das ovelhas, mesmo em condições de lactação prolongada. Esse resultadoé de vital importância no sistema de parição acelerada, na qual se desejam três partos a cada dois anos. Esse sistema pode ser viabilizado com a utilização do creepfeeding e, desde que a estação do ano comporte o aparecimento de atividade reprodutiva, pode-se efetivar uma estação de reprodução intermediária. Os resultados obtidos nesta pesquisa mostram que não obstante a época ser apropriada à reprodução, as ovelhas encontravam-se em bom estado corporal. Portanto, a não manifestação de cios pós-parto, em todos os tratamentos, foi de todo inesperada.

Em dois ensaios anteriores, idênticos a este experimento, obtiveram-se respostas efetivas de aparecimento de cios mesmo em épocas totalmente inesperadas (dados não publicados). Também em um ciclo subseqüente na continuação deste trabalho, foi obtido retorno ao cio em cerca de $95 \%$ das ovelhas paridas, antes de 60 dias pós-parto. Estes resultados foram obtidos com ovelhas não suplementadas, com desmama feita aos 60 dias, nos moldes idênticos ao presente experimento (dados não publicados). Os resultados desfavoráveis obtidos podem ser atribuídos ao fato de as ovelhas utilizadas provierem de manejo acelerado de reprodução, onde foram utilizadas indução hormonal e sincronização de cios.

\section{Conclusões}

A utilização de creep-feeding permitiu retardamento da idade à desmama dos cordeiros Hampshire Down e quando foram desmamados aos 62 dias de idade atingiram o peso de abate sem necessitar de confinamento. Os resultados demonstraram que cordeiros desmamados aos 62 dias com auxílio de creep-feeding apresentaram menor idade ao abate e características mais desejáveis para a carcaça, como melhor rendimento e compacidade. Além disso, a precocidade de abate não permitiu deposição excessiva de gordura nas carcaças dos cordeiros, mesmo quando criados em regime intensivo dentro de um sistema de produção de ciclo curto. A suplementação das matrizes nas condições do experimento não melhorou o desempenho de cordeiros, embora os resultados indiquem que o leite das ovelhas teve papel importante no comportamento de ganho de peso dos cordeiros deste experimento.

É interessante e recomendável uma continuação do experimento, em que verifiquem, de forma conclusiva, o retorno ao cio das matrizes no pós-parto, a produção de leite e a conversão alimentar de cordeiros, bem como o seu comportamento frente a infestações de parasitose gastrintestinal.

\section{Literatura Citada}

ARANA, A.; SORET, B.; MENDIZABAL, J.A. et al. Changes in adipose tissue accumulation in rasa Aragonesa breed lambs during growth and fattening. Animal Science, v.66, n.2, p.409-13, 1998.

ARNOLD, A.M.; MEYER, H.H. Effects of gender, time of castration, genotype and feeding regimen on lamb growth and carcass fatness. Journal of Animal Science, v.66, p.2468, 1988.

ATTAIX, D.; MESLIN, J.C. Changes in small intestinal mucosa morphology and cell renewal in suckling, prolonged-suckling and weaned lambs. Animal of Journal Physiology, v.261, n.30, p.811-18, 1991.

BLACKBURN, H.D.; SNOWDER, G.D.; GLIMP, H. Simulation of lean lamb production systems. Journal of Animal Science, v.69, p.115-24, 1991.

CHEMINEUAU, P.; MALPAUX, B.; GUÉRIN, Y. et al. Lumière et mélatonine pour la maitrise de lá reproduction des ovins et des caprins. Annales Zootechnie, v.41, p.246-61, 1992.

CROUSE, J.D.; BUS BOOM, J.R.; FIELD, R.A. et al. The effects of breed, diet, sex, location and slaughter weight on lamb growth, carcass composition and meat flavor. Journal of Animal Science, v.53, n.3, p.376-86, 1981.

ELY, D.G.; GLENN, B.P.; MAHYUDDIN, M. et al. Drylot vs Pasture: Early-weaned performance to two slaughter weights. Journal of Animal Science, v.48, p.32, 1979.

FOGARTY, N.M.; HALL, D.G.; DAWE S.T. et al. Management of highly fecund ewe types and their lambs for 8-monthly lambing. 1.Effect of lamb weaning age on ewe reproductive activity in spring. Australian of Journal Experimental Agriculture, v.32, n.4, p.421-8, 1992.

FOLCH, J. Utilization Practica del "Efecto Macho" para la provocación de celos y ovulaciones en ganado ovino. ITEA, v.86A, n.3, p.145-63, 1990.

FOLCH, J; PURROY, A.; VALDERRABANO, J. Influencia de la alimentación sobre la reproducción de la oveja. Revista Ovis, v.13, p.9-23, 1991.

FOLMAN, Y.; EYAL, E.; VOLCANI, R. Mother-offspring relationships in Awassi sheep. Milk Yields and weight gains of lambs in a mutton flock. Journal of Agriculture Science, v.67, p.369-70, 1966a.

FOLMAN, Y.; EYAL, E.; VOLCANI, R. Mother-offspring relationships in Awassi sheep. The effect of different suckling regimes and weaning age on weight gains of lambs in dairy flocks. Journal of Agriculture Science, v.67, p.371-376, 1966b.

FOOT, J.Z. A note on the effect of body condition on the voluntary intake of dried grass wafers by Scottish Blackface ewes. Animal Production, v.14, p.131-4, 1972.

HATFIELD, P.G.; SNOWDER, G.D.; HEAD J.R. et al. Production by ewe rearing single or twin lambs: effects of dietary crude protein percentage and supplemental zinc methionine. Journal of Animal Science, v.73, p.1227-1238, 1995. 
JENKINS, T.G. Postweaning performance and carcass characteristics of crossbred ewe lamb produced in accelerated or annual lambing systems. Journal of Animal Science, v.63, p.1063-71, 1986.

JORDON, R.M.; MARTEN, G.C. Effect of weaning, age at weaning and grain feeding on the performance and production of grazing lambs. Journal of Animal Science, v.27, n.1, p.174-177, 1968.

MANDIKI, S.N.M.; BISTER, J.L.; PARQUAY, R. Effects of suckling mode on endocrine control of reproductive activity resumption in Texel ewes lambing in July or November. Theriogenology, v.33, p.397-413, 1990.

MANSO, T.; MANTECÓN A.R.; CASTRO, T. et al. Effect of intake level during milk-feeding period and protein content in post-weaning diet on the performance and body composition in growing lambs. Animal Science, v.67, p.513-521, 1998.

MITCHELL, L.M.; KING, M.E.; GEBBIE, F.E. et al. Resumption of estrous and ovarian cyclicity during the postpartum period in autumn-lambing ewes is not influenced by age or dietary protein content. Animal Science, v.67, n.1, p.65-72, 1998.

MURPHY T, A.; LOERCH, S.C.; MCCLURE, K.E. et al. Effects of grain or pasture finishing on carcass composition and tissue accretion rates of lambs. Journal of Animal Science, v.72, p.3138-44, 1994.

NATIONAL RESEARCH COUNCIL - NRC. Nutrient requirements of sheep. 6.ed. Washington, D.C.: National Academy Press, 1985. 99p.

NOTTER, D.R.; MCCLAUGHERTY. Effects of breed and management system on efficiency of lamb production: ewe productivity. Journal of Animal Science, v.69, p.13-21, 1991.

NOTTER, D.R.; KELLY, R.F.; MCCLAUGHERTY. Effects of ewe breed and management system on efficiency of lamb production: lamb growth, survival and carcass characteristics. Journal of Animal Science, v.69, p.22-23, 1991.

PEETERS, R.; KOX, G.; ISTERDAEL, J.V. Environmental and genetic influence on growth performance of lambs in different fattening system. Small Ruminants Research, v.18, p.5767, 1995

POLLOT, G.E.; KILKENNY, J.B. Carne. In: Nuevas tecnicas de producción ovina, 1994. p.13-28.

RAMSEY W.S.; HATFIELD P.G.; WALLACE J.D. et al. Relationship among ewe milk production and ewe and lamb forage intake in Targhee ewes nursing single or twin lambs. Journal of Animal Science, v.72, n.4, p.811-816, 1994.

RATTRAY, P.V.; GARRET, W.N.; HINMAN, N. et al. Effects of level of nutrition pregnancy and age on the composition of the wool-free ingest free body and carcass sheep. Journal of Animal Science, v.39, n.4, p.687-93, 1974.
ROUSE G.H.; TOPEL D.G.; VETTER R.L. et al. Carcass Composition of lambs at different stages of development. Journal Agriculture Science, p.846-55, 1970.

SAÑUDO, C.; SIERRA, I. Calidad de la canal en la espécie ovina. Revista Ovis, n.1, p.127-53, 1986.

SAS procedures guide. Release 6. 3 ed. Cary, 1989. 1686p.

SILVA, L.F.; PIRES, K.C. Avaliações quantitativas e predição das proporções de osso, músculo e gordura da carcaça em ovinos. Revista Brasileira de Zootecnia, v.29, n.4, p.1253-1260, 2000.

SNEDECOR, G.W.; COCHRAN, W.G. Statistical methods. 6.ed. Ames: Iowa State University Press, 1978. 593p.

SUMMERS, R.L.; KEMP, J.D.; ELY, D.G.; et al. Effects of weaning, feeding systems and Sex of lamb on the carcass characteristics and palatability. Journal of Animal Science, v.47, n.3, p.622-629, 1978.

SUSIN, I. Exigências nutricionais de ovinos e estratégias de alimentação. In: Nutrição de ovinos. Jaboticabal, 1.ed. 1996, p.119-41.

WAGHORN, G.C.; SMITH, J.F.; ULYATT, M.J. Effect of protein and energy intake on digestion and nitrogen metabolism in wethers and on ovulation in ewes. Animal Production, v.51, p.291-300, 1990.

WALLACE, J.M.; ROBINSON, J.J.; MCKELVEY, W.A.C. et al.. Studies on increasing breeding frequency in the ewe. 2 The endocrine status of lactating ewes induced to ovulate 28, 35 or 42 days post-partum. Animal Reproduction Science, v.18, p.271-83, 1989.

WHEELER, T.L.; KOOHMARAIE, M.; SHACKELFORD, S.D. Standardized warner-bratzler shear force procedures for meat tenderness measurement. Roman L. Hruska U. S. MARC. USDA, Clay Center, NE. 1995.

WILSON, L..; VARELA-ALVAREZ, H.; CHRISTINE, E. et al. Influence of energy level, creep feeding and lactation stage on ewe milk and lamb growth characters. Journal of Animal Science, v.33, n.3, p.686-90, 1971. 